Research Article

\title{
Degradation of Shotcrete Materials Subjected to Sulfate and Chloride Attack in Varying Exposure Regimes
}

\author{
Ruiqiang Zhao, ${ }^{1}$ Lihao Xu $\mathbb{D}^{1},{ }^{1}$ Jun Yang, ${ }^{2}$ Yang Zou $\mathbb{D}^{,},{ }^{2}$ and Zhongya Zhang $\mathbb{D}^{2,3}$ \\ ${ }^{1}$ School of Materials Science and Engineering, Chongqing Jiaotong University, Chongqing 400074, China \\ ${ }^{2}$ State Key Laboratory of Mountain Bridge and Tunnel Engineering, Chongqing Jiaotong University, Chongqing 400074, China \\ ${ }^{3}$ School of Civil Engineering, Chongqing Jiaotong University, Chongqing 400074, China
}

Correspondence should be addressed to Zhongya Zhang; zhangzhongya@cqjtu.edu.cn

Received 16 June 2021; Revised 25 July 2021; Accepted 29 September 2021; Published 11 October 2021

Academic Editor: Guoming Liu

Copyright (c) 2021 Ruiqiang Zhao et al. This is an open access article distributed under the Creative Commons Attribution License, which permits unrestricted use, distribution, and reproduction in any medium, provided the original work is properly cited.

Durability of in situ shotcrete under external sulfate attack was investigated, taking into consideration the addition of mineral admixtures, along with the presence of chloride ions. Three water-to-binder ratios (w/b), i.e., $0.35,0.45$, and 0.55 , and two types of supplementary cementitious materials (SCMs), namely, fly ash (FA) and silica fume (SF), were considered in the current study. Two different laboratorial immersion regimes (continuously full immersion and partial immersion with cycling temperature and relative humidity) were carried out to induce chemical/physical sulfate attack. Results show that loss of strength was the typical feature of chemical sulfate attack on shotcrete, while surface spalling dominated in deterioration caused by physical sulfate attack. The presence of chloride ions can globally mitigate these deteriorations. Meanwhile, the lower w/b ratio proved to be efficient in increasing the resistance to both sulfate attacks. Adding fly ash (FA) in shotcrete mixtures enhanced the long-term performance but invited massive white efflorescence on surface layer under partial-immersion exposure condition. Silica fume (SF) admixture can compensate the undesired reduction of early-age strength caused by FA addition, but make these specimens more susceptible to sulfate attack. Mercury intrusion porosimetry (MIP) analysis, scanning electron microscopy (SEM), and X-ray diffraction (XRD) tests reveal that these consequences were strongly related to the refinement of microstructure resulted from pozzolanic reactions and hydration kinetics.

\section{Introduction}

Durability of cement-based materials, no matter emerging or conventional ones, has become a major issue in structural engineering over the last few decades [1,2]. Among them, shotcrete durability is generally overlooked due to the reliable performance benefited from its technology of high speed jet, high early-age strength and the addition of the accelerator, which differs from conventional concrete materials [3]. However, they have the risk to be eroded by contaminated groundwater under harsh ambient environments, such as shotcrete liners of a tunnel underneath a refuse landfill. This groundwater is deleterious to shotcrete materials since it was contaminated by certain pernicious species, e.g., $\mathrm{SO}_{4}^{2-}$ and $\mathrm{Cl}^{-}$or the combination of two. These ions have adverse impact on the durability of porous shotcrete materials, such as a collapse of mechanical strength. Free chloride ions mainly corrode the reinforcement steel, and sulfate salt attacks the concrete pastes inch by inch $[4,5]$. Meanwhile, chloride ions were also detected to degrade cement pastes [5]. These adverse impacts may cause deterioration or even disintegration of shotcrete materials during service period. Since permanent shotcrete linings are increasingly adopted in road slope and underground tunneling engineering, durability of shotcrete under these aggressive environments is becoming crucial at the design and construction stage. Unfortunately, there is dearth of information on sulfate resistance of shotcrete materials in the presence of chloride ions. The corresponding performancebased testing was also rarely reported.

Shotcrete materials usually directly contact with groundwater or rock mass. The individual damage mechanisms caused by these ions on cement-based materials were well-documented in the last few decades [6-11]. Among 
them, sulfate expansive products such as ettringite (E), gypsum (G), and thaumasite (T) and crystallization of sulfate salt (mainly sodium sulfate) are regarded as two main hypotheses [12-19]. As for chloride-induced damage, it is generally believed that $\mathrm{Cl}^{-}$may combine with the $\mathrm{C}_{3} \mathrm{~A}$ phase to generate Friedel's salt [20-25]. However, dedicated durability studies on the sulfate resistance of shotcrete materials mixed with fly ash (FA)/silica fume (SF) were rare. This is mainly due to that in situ preparation of shotcrete materials is difficult and uncontrollable. Moreover, construction deficiency such as cavity may widely exist during the preparation of shotcrete materials, thus largely reducing the reliability of tests. In addition, many researchers studied the effects of exposure regimes on the sulfate attacking mechanism on concrete materials [26-30]. In these reports, it can be concluded that full immersion or partial immersion of concrete specimens in $\mathrm{Na}_{2} \mathrm{SO}_{4}$ solutions may result in different damages on concrete [31-38]. For dry-mix shotcrete, the $w / b$ ratio is controlled by the volume of water mixing in the jet, rather than changing the amount of cementing materials. Clearly, this process greatly depends on the experience of workers, although predesign was well done. Thus, many studies on shotcrete shift the preparation stage to indoor, using small spray devices. However, this also alters the nature of shotcrete property, reducing reliability of the obtained results. On-site fly ash (FA) and silica fume (SF) are usually used to enhance the performance of shotcrete materials under various ambience environments [39]. Due to early-age strength of shotcrete is ensured by the addition of accelerator, thus, FA is added in the system to increase the long-term strength and workability. This is expected to increase the durability of shotcrete under severe exposure conditions. The early-age strength of shotcrete with addition of fly ash was reduced; silica fume can well compensate this deficiency [2]. However, durability of in situ mixing FA/SF shotcrete under sulfate-rich environments in presence of chloride ions remains to be thoroughly tested. Large number of researchers focused on chloride-induced corrosion of steel reinforcements $[21,23,24]$. In addition, only a few studies concerned on combined $\mathrm{Cl}^{-}$and $\mathrm{SO}_{4}^{2-}$ attacking concrete materials $[14,25]$. In these research studies, full immersion of concrete specimens in $\mathrm{MgSO}_{4}$ with the coexistence of $\mathrm{NaCl}$ was mainly performed [25]. Clearly, the deterioration caused by $\mathrm{MgSO}_{4}$ was mitigated or even delayed by the coexistence of $\mathrm{NaCl}$ from the results of these recent studies $[14,25]$.

Concerning the chloride-induced corrosion or sulfate attack mechanism on concrete materials, a number of achievements have been reported [40-45]. However, dedicated studies concerning sulfate resistance of shotcrete materials in presence of chloride ions are scarce. Most reports with respect to shotcrete materials mainly focused on development of accelerator products, additive or spray equipment, primarily aiming at enhancing the early-age strength and reducing rebound ratio [46-52]. In this study, thus a laboratory-scale accelerated corrosion test on shotcrete specimens $\left(100 \mathrm{~mm}^{3}\right.$ cube) exposed to sodium sulfate solutions was performed, taking into account the presence of chloride ions. The erosion solutions were made using pure solution of $5 \% \mathrm{w} / \mathrm{w} \mathrm{Na}_{2} \mathrm{SO}_{4}(\mathrm{~S})$ and a mixed solution of $5 \%$ w/w $\mathrm{Na}_{2} \mathrm{SO}_{4}$ and $5 \% \mathrm{w} / \mathrm{w} \mathrm{NaCl}$ (SC). In this way, the deterioration mechanism of shotcrete specimens exposed to $\mathrm{Na}_{2} \mathrm{SO}_{4}$ solution in the presence of $\mathrm{Cl}^{-}$was preliminarily explored, by means of different analytical techniques and evaluation indicators.

\section{Experimental Program}

2.1. Materials. Universal ordinary portland cement (OPC, intermediate levels of OPC, C3A was 9\%, P.O.42.5) was used as the main cementitious material (CMs). Two types of supplementary cementing materials (SCMs), i.e., Class I fly ash (FA) and silica fume (SF) were used as partial replacement of OPC to make binary binders. The low alkaline accelerator (AC), which contained $\mathrm{NaAlO}_{2}$ and $\mathrm{Ca}_{2} \mathrm{SiO}_{4}$ $\left(\mathrm{C}_{2} \mathrm{~S}\right)$ as the main components, was used at a dose of $2.27 \%$ of the total binder content (i.e., $10.55 \mathrm{~kg} / \mathrm{m}^{3}$ ). Polycarboxylic acid (HRWRA) with a water reducing rate of $22.8 \%$ was used as a water reducing agent, and its dosage is $0.8 \%$ of the total binder content $\left(3.712 \mathrm{~kg} / \mathrm{m}^{3}\right)$. The details of the used materials are provided in Table 1.

Fine aggregate used in this study is natural river sand, fineness modulus is 2.61 , having a continuous rating and a maximum size of $12 \mathrm{~mm}$ in the gravel as coarse aggregate. The specific gravity $\left(\mathrm{kg} / \mathrm{m}^{3}\right)$ is 2650 and absorption (\%) is 0.61 . Both aggregates meet the requirements of JGJ/T 3722016 [35] and JGJ 52-2006 [36].

2.2. Specimen Preparation. Single and binary binders were prepared using these pozzolana materials and cement $(C)$. The dosage of mineral admixtures is at weight percentage (w/w) by the total binder content, as partially replacement of OPC. The detailed proportions of binders are summarized in Table 2. Different ratios of water-to-binder (w/b) were adopted in mixtures made by OPC.

The total cementitious materials $(\mathrm{CM}+\mathrm{SCMs}=\mathrm{b})$ content was kept constant at $464 \mathrm{~kg} / \mathrm{m}^{3}$ for all binders in the current study. Seven concrete mixtures were tested in this study. Single binder (control) mixtures were prepared from $100 \%$ OPC, in which three w/b ratios $(0.35,0.45$, and 0.55$)$ were considered. Other two mixtures were prepared from blended binders with a certain replacement level of OPC having a uniform $w / b$ ratio of 0.45 . The proportions of the mixed design are listed in Table 3.

In the present experiment, the concrete mixture is prepared in line with JGJ/T 372-2016 [35]. The w/b ratio is controlled by the amount of water, and the cement is controlled. The design ratio of the mixture is shown in Table 3, which meets the requirements of JGJ/T 372-2016 [35], GB/T 50082-2009 [37], and GB/T 50081-2002 [38].

2.3. Exposure Regimes. After 28 days of initial curing, the shotcrete samples were immersed in mixed solutions (containing 5\% w/w sodium sulfate alone (S) and 5\%w/w sodium sulfate and 5\% w/w sodium chloride (SC)) under different regimes. In addition, these solutions were prepared by dissolving anhydrous sodium sulfate $\left(\mathrm{Na}_{2} \mathrm{SO}_{4}\right)$ and 
TABle 1: Chemical compositions and physical properties of cementitious materials and supplementary cementing materials [2].

\begin{tabular}{|c|c|c|c|c|}
\hline \multirow{2}{*}{ Components/properties (w/w) } & \multirow{2}{*}{$\begin{array}{l}\text { CMs } \\
\text { OPC }\end{array}$} & \multicolumn{2}{|c|}{ SCMs } & \multirow{2}{*}{$\begin{array}{l}\text { Admixture } \\
\text { Accelerator }\end{array}$} \\
\hline & & FA & SF & \\
\hline \multicolumn{5}{|l|}{ Chemical compositions (\%) } \\
\hline Silicon oxide $\left(\mathrm{SiO}_{2}\right)$ & 19.7 & 48.9 & 94.0 & 14.63 \\
\hline Aluminum oxide $\left(\mathrm{Al}_{2} \mathrm{O}_{3}\right)$ & 5.12 & 23.3 & 0.1 & 18.79 \\
\hline Ferric oxide $\left(\mathrm{Fe}_{2} \mathrm{O}_{3}\right)$ & 2.41 & 14.9 & 0.1 & 4.14 \\
\hline Calcium oxide $(\mathrm{CaO})$ & 60.5 & 3.8 & 0.4 & 32.73 \\
\hline Magnesium oxide $(\mathrm{MgO})$ & 3.31 & 0.7 & 0.4 & 0.65 \\
\hline Sulfur trioxide $\left(\mathrm{SO}_{3}\right)$ & 3.01 & 0.2 & 1.3 & 0.27 \\
\hline \multicolumn{5}{|c|}{ Compound composition of clinker (\%) } \\
\hline Tricalcium silicate $\left(\mathrm{C}_{3} \mathrm{~S}\right)$ & 61.8 & & & \\
\hline Dicalcium silicate $\left(\mathrm{C}_{2} \mathrm{~S}\right)$ & 12.1 & & & \\
\hline Tricalcium aluminate $\left(\mathrm{C}_{3} \mathrm{~A}\right)$ & 9.1 & & & \\
\hline $\begin{array}{l}\text { Tetracalcium aluminoferrite } \\
\left(\mathrm{C}_{4} \mathrm{AF}\right)\end{array}$ & 7.6 & & & \\
\hline \multicolumn{5}{|l|}{ Physical properties } \\
\hline Loss on ignition (\%) & 2.5 & 0.3 & 4.7 & \\
\hline Specific surface area $\left(\mathrm{m}^{2} / \mathrm{kg}\right)$ & 410 & 280 & 19530 & \\
\hline Specific gravity & 3.17 & 2.08 & 2.12 & \\
\hline
\end{tabular}

TABLE 2: Design proportions of blended binders.

\begin{tabular}{lc}
\hline Binders & Proportions \\
\hline 1 & $100 \%$ Ordinary Portland Cement \\
2 & $90 \%$ OPC $+10 \%$ w/w fly ash \\
3 & $90 \%$ OPC $+10 \% \mathrm{w} / \mathrm{w}$ silica fume \\
\hline
\end{tabular}

TABLE 3: Design of the mixing ratio of shotcrete mixtures per cubic meter.

\begin{tabular}{lccccc}
\hline Materials & PC35 & PC45 & PC55 & FA10 & SF10 \\
\hline OPC (kg) & 464 & 464 & 464 & 418 & 418 \\
FA (kg) & & & & 46 & \\
SF (kg) & & & & & 45 \\
Coarse aggregate (kg) & 907 & 907 & 907 & 907 & 907 \\
Fine aggregate (kg) & 890 & 890 & 890 & 890 & 890 \\
Accelerator (kg) & 10.55 & 10.55 & 10.55 & 10.55 & 10.55 \\
Water reducing (kg) & 3.712 & 3.712 & 3.712 & 3.712 & 3.712 \\
Water (kg) & 162.4 & 208.8 & 255.2 & 208.8 & 208.8 \\
w/b (w/w) & 0.35 & 0.45 & 0.55 & 0.45 & 0.45 \\
\hline
\end{tabular}

sodium chloride $\left(\mathrm{Na}_{2} \mathrm{Cl}\right)$ with a specified amount of water. All solutions were renewed monthly and the $\mathrm{pH}$ was controlled at a range of $6.0-8.0$ by titration with diluted sulfuric acid solutions at regular time intervals (15 days). In this study, two exposure regimes were simultaneously carried out for a comprehensive comparison, i.e., continuously full immersion and partial immersion with cycling temperature and RH (relative humidity). They are described as follows:

(a) The regime of continuously full immersion is to fully submerge the cubic specimens within the erosion solutions up to 10 months, as shown in Figure 1.

(b) The regime of partial immersion is similar to the method by Nehdi et al. [19] in which the cubic specimens were partially submerged in erosion solutions subjected to cycles of temperature and $\mathrm{RH}$, as shown in Figure 2. One cycle (15 days) consisted of two phases: 8 days of wetting curing at temperature of $20 \pm 2^{\circ} \mathrm{C}$ and $\mathrm{RH}$ of $90 \pm 5 \%$, followed by 7 days of the drying phase at $45 \pm 2^{\circ} \mathrm{C}$ and $35 \pm 5 \% \mathrm{RH}$ in an environmental chamber. A total of 10 cycles (5 months) was performed in this study.

\subsection{Tests}

2.4.1. Mass Variation. Before testing, the spray cubes tested were air-dried in the laboratory at a temperature of $23^{\circ} \mathrm{C}$ $\left(73.4^{\circ} \mathrm{F}\right)$ and a relative humidity of $70 \%$ until a constant mass was reached. Then, the mass of shotcrete cubic specimens at erosion time $t$, i.e., $m_{t}$, was measured using a balance with an accuracy of $0.01 \mathrm{~g}$. Then, calculate the mass change according to

$$
\text { Mass variation at }=\frac{\left(m_{e}-m_{0}\right)}{m_{0}} \times 100 \%,
$$

where $m_{0}$ is the initial mass before exposure and $m_{e}$ is the mass of shotcrete cubic specimen after exposure period.

2.4.2. Strength. Compressive strength of the shotcrete cubic specimens under all regimes in erosion solutions was measured according to the GB 50081-2002 [38] (standard for the method of mechanical properties on ordinary concrete). All tests were performed on three identical samples, and the average of the three was used. Subsequently, the strength variation was calculated according to

$$
\text { Strength variation at }=\frac{\left(\sigma_{e}-\sigma_{0}\right)}{\sigma_{0}} \times 100 \%,
$$

where $\sigma_{0}$ is the initial strength before exposure and $\sigma_{e}$ is the strength of shotcrete cubic specimen after exposure period.

2.4.3. Microanalysis. Scanning electron microscopy (SEM) with energy dispersive X-ray analysis (EDX) are performed to study the microstructure and morphology of minerals in the deteriorating sample. At the specified time, let the sample air dry in the laboratory until no water is visible. Then, some of them were broken up and small debris (diameter less than $11 \mathrm{~mm}$ ) was collected from different portions of samples. The collected debris was dried using a desiccator and then coated with gold on the surface before the SEM and EDX testing. The compositions of the corrosion products were analyzed using X-ray diffraction (XRD). After the exposure period, the deteriorating shotcrete specimens were taken out from the container. They were air-dried in the laboratory until no water can be seen. Then, some of them were broken up and small debris was collected from different portions of the specimen. The collected debris from identical portions was ground, and the obtained powder samples were going to pass the $200 \mu \mathrm{m}$ sieve before the XRD testing.

2.4.4. Pore Structure. After 28 days of standard curing, small pieces were retrieved from selected samples to evaluate the pore size distribution using mercury intrusion porosimetry (MIP). 


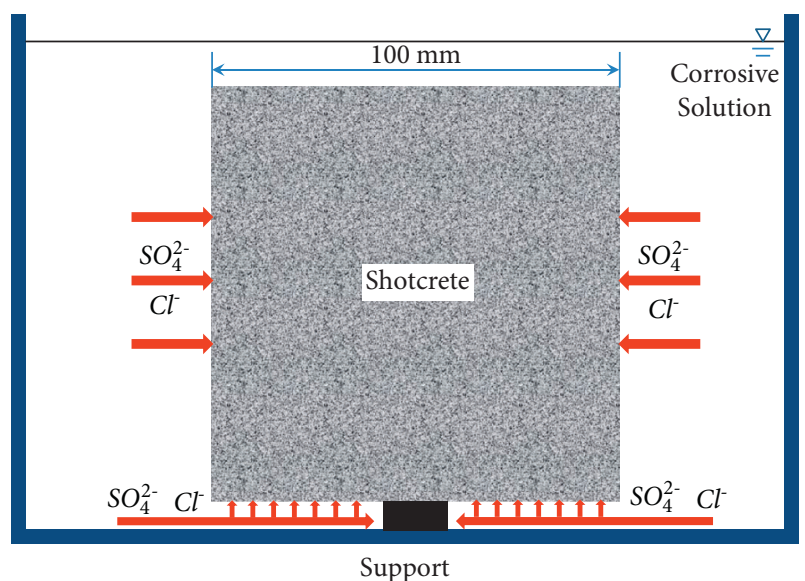

FIgURE 1: Continuously full immersion.

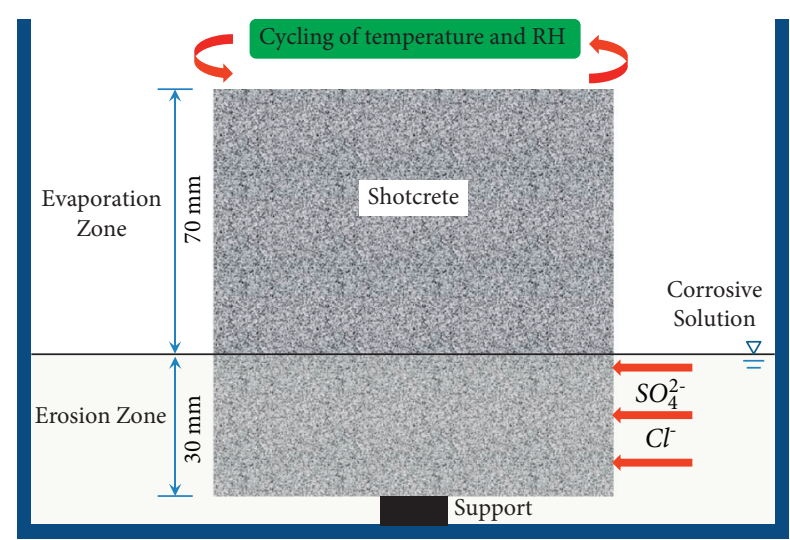

Figure 2: Partial immersion subjected to cycles of temperature and $\mathrm{RH}$.

More specifically, the collected fragments were immediately plunged in an isopropanol solvent to stop cement hydration reactions. These samples were subsequently dried inside a desiccator until a constant mass was reached. The MIP measurements were performed using a MIP machine (Micromeritics AutoPore IV 9500). The surface tension was assumed to be $480 \mathrm{mN} / \mathrm{m}$, and the contact angle was assumed to be $130^{\circ}$ according to ASTM D4404 [53] (Standard Test Method for Determination of Pore Volume and Pore Volume Distribution of Soil and Rock by Mercury Intrusion Porosimetry).

\section{Results}

\subsection{Continuously Full Immersion}

3.1.1. Visual Inspection. The pore size distribution of various shotcrete mixtures measured by MIP is shown in Figure 3. The blended binary binders with addition of FA or SF have finer pore structures compared to the plain binders made with pure OPC. The total pore volume of various specimens follows $\mathrm{PC}>\mathrm{FA} 10>$ SF10. For PC specimens, a lower w/b ratio results in a lower intruded pore volume. Mixtures made by OPC with a w/b ratio of 0.35 possess the lowest intruded pore volume. In addition, the mixtures incorporating $10 \%$ SF have the large volume of small pores $(<0.05 \mu \mathrm{m}$ in diameter).

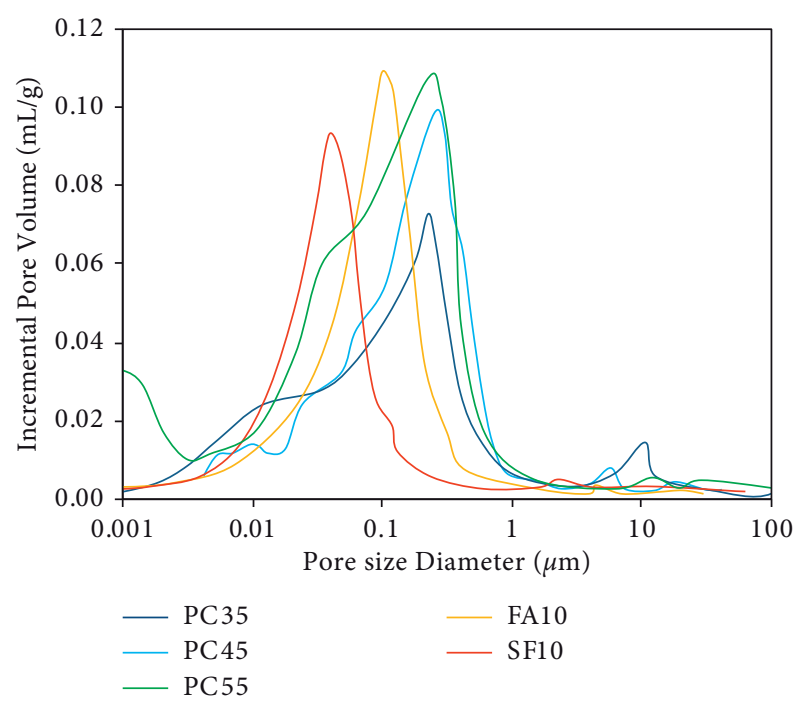

FIGURE 3: MIP results of specimens from various shotcrete mixtures before exposure.

After 10 months of continuously full immersion in both erosion solutions ( $\mathrm{S}$ and $\mathrm{SC}$ ), all shotcrete specimens remained visually intact except the specimens incorporating $10 \%$ SF (SF10). Overall, FA10 exhibited better resistance to surface deterioration in comparison with that of PC specimens. This may be attributed to consumption of calcium hydroxide $(\mathrm{CH})$ in pozzolanic reactions, while it is the most vulnerable component under the ingress sulfate ions. Meanwhile, this process can increase the compactness of shotcrete, thereby to enhance permeability and porosity. Such refinement effect can reduce the formation of deleterious compounds such as ettringite and gypsum [28]. In addition, high aluminium oxide $\left(\mathrm{Al}_{2} \mathrm{O}_{3}\right)$ and low tri-calcium aluminate $\left(\mathrm{C}_{3} \mathrm{~A}\right)$ content in FA10 specimens was not conducive to ettringite formation [8].

However, surface deterioration of SF10 was the most intense (see Figure 4), which signified the worst resistance to sulfate attack in comparison with others. This behavior was due to that low aluminium oxide $\left(\mathrm{Al}_{2} \mathrm{O}_{3}\right)$ content in the SF system was favor to the formation of thaumasite $\left(\mathrm{CaSiO}_{3}\right.$ $\mathrm{CaCO}_{3} \mathrm{CaSO}_{4} 15 \mathrm{H}_{2} \mathrm{O}$ ) in SF10 specimens, as confirmed by XRD analysis shown in Figure 5. Since the XRD pattern of thaumasite is similar to ettringite, some main peaks are almost overlapping, such as the peak of $16^{\circ} 2 \theta$. Thus, we must identify thaumasite from some weak peaks, such as $26^{\circ} 2 \theta$ and $28^{\circ} 2 \theta$.

It was reported that the formation of thaumasite can be a result of the reaction between calcium silicate hydrate, sulfate, and carbonate ions at low temperatures $\left(0-5^{\circ} \mathrm{C}\right)$ and excess humidity environments [39]. However, thaumasite was also detected under CSA at higher temperature conditions [40]. Meanwhile, low $\mathrm{Al}_{2} \mathrm{O}_{3}$ content of SF binders resulted in a high $\mathrm{SO}_{3} / \mathrm{Al}_{2} \mathrm{O}_{3}$ mole ratio in the system, which was prerequisite for thaumasite attack. Since calcium silicate hydrate $(\mathrm{C}-\mathrm{S}-\mathrm{H})$ is necessary for thaumasite formation, this attack gradually destroys the binding ability of the cement paste by transforming C-S-H gels into a mush. For SF10 


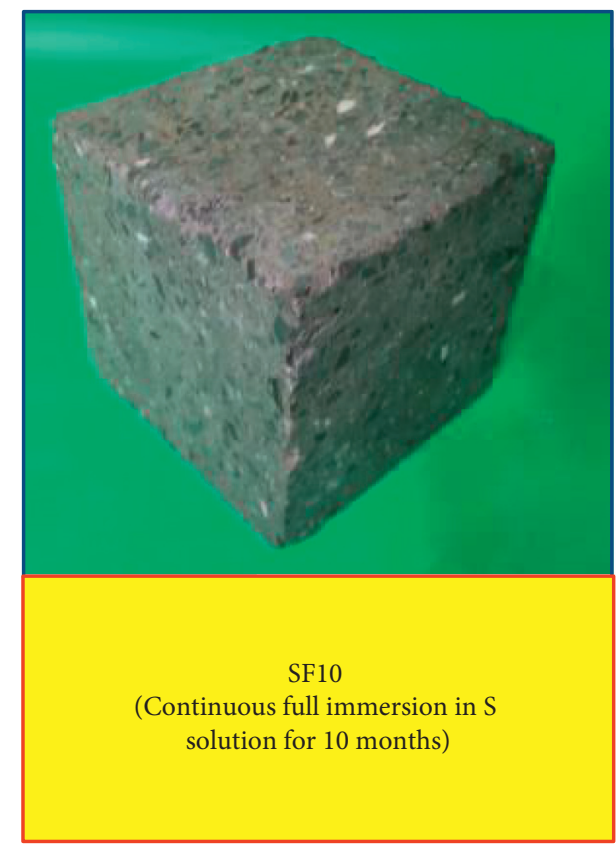

(a)

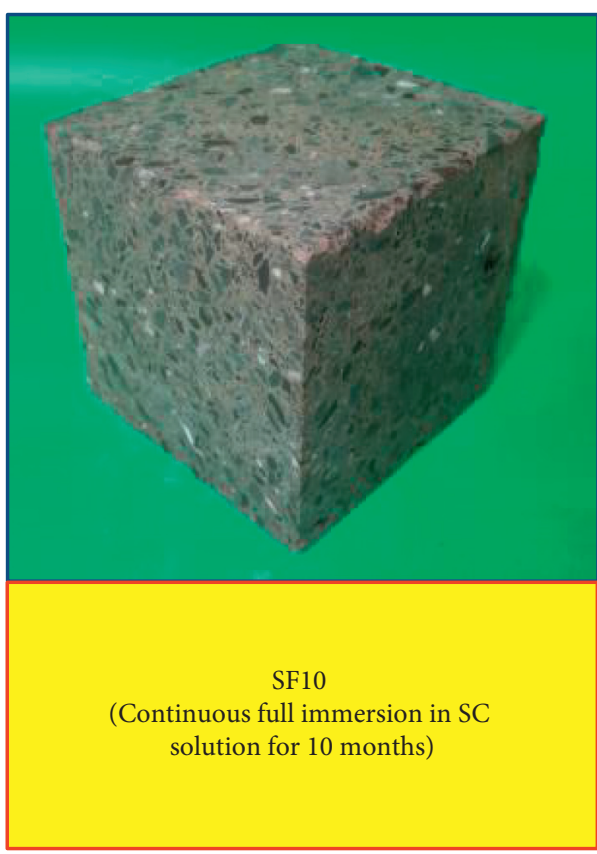

(b)

FiguRE 4: Visual appearance of SF10 specimens after exposure.

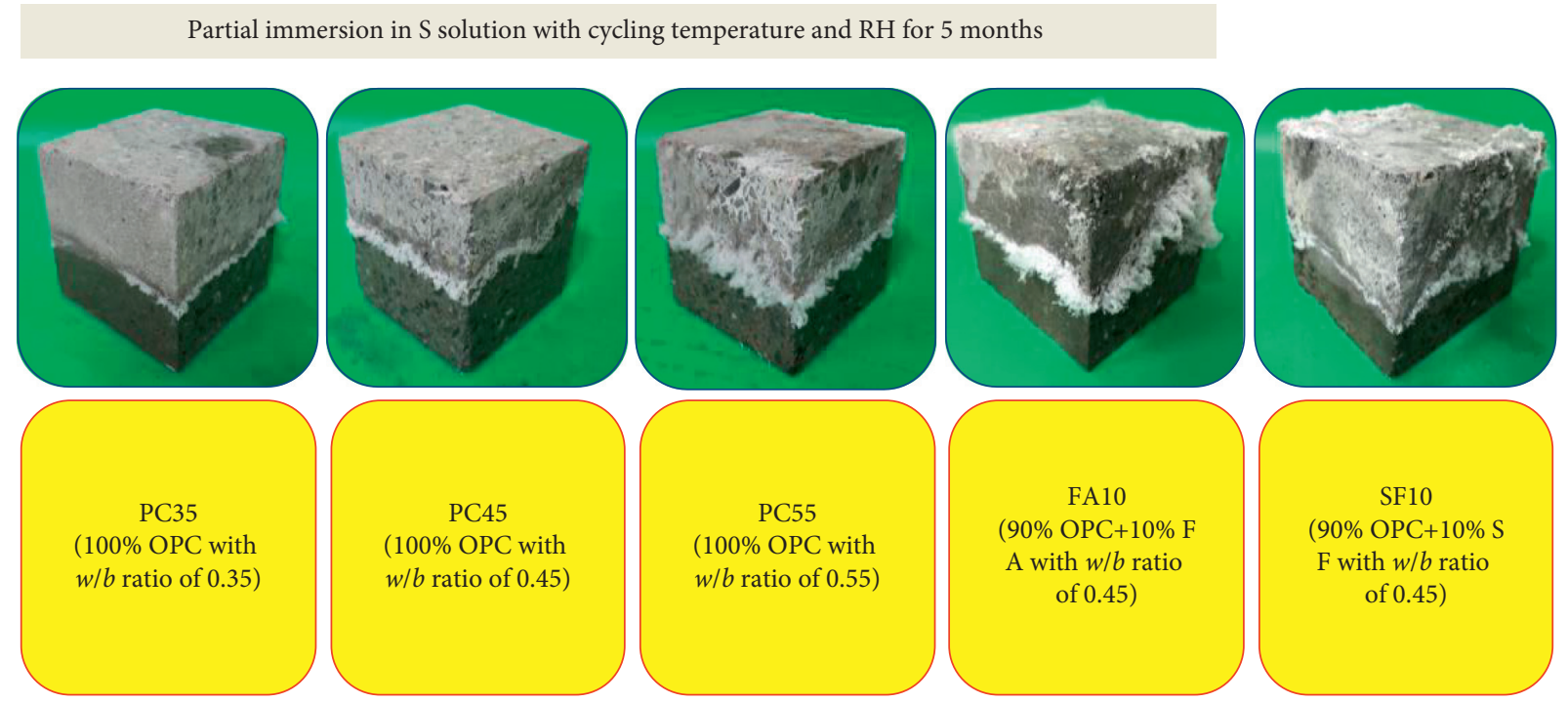

FIGURE 5: Visual appearance of various shotcrete specimens partially immersed in S solutions subjected to cycles of temperature and RH for 5 months.

specimens, spalling along the edges began at around 8 months of immersion. As can be seen, loss of cementitious matrix-aggregate bond was observed along the edges of specimens. As a consequence, edges and corners of the specimen were smoothed down. Moreover, the degree of surface deterioration of SF10 specimen in S solution was higher than that of SF10 specimen in SC solution. It has been well established that chloride can mitigate chemical sulfate attack on cement-based materials $[14,15]$. Since the faster penetration capability of free chloride ions than that of sulfate ions, chloride may firstly combine with $\mathrm{C}_{3} \mathrm{~A}$ and calcium hydroxide $(\mathrm{CH})$ to form Friedel's salt $\left(3 \mathrm{CaO} \mathrm{Al}_{2} \mathrm{O}_{3}\right.$ $\mathrm{CaCl}_{2} 10 \mathrm{H}_{2} \mathrm{O}$ ) before sulfate arrived. The possible reaction is expressed by

$$
\begin{aligned}
& \mathrm{Ca}(\mathrm{OH})_{2}+2 \mathrm{NaCl}^{\circledR} \mathrm{CaCl}_{2}+2 \mathrm{Na}+2 \mathrm{OH} \\
& \mathrm{CaCl}_{2}+\mathrm{C}_{3} \mathrm{~A}+10 \mathrm{H}_{2} \mathrm{O} \longrightarrow \mathrm{C}_{3} \mathrm{~A} \cdot \mathrm{CaCl}_{2} \cdot 10 \mathrm{H}_{2} \mathrm{O} \text { (Friedel's salt). }
\end{aligned}
$$

These products thus can block tiny pores and cracks in the system, delaying or mitigating sulfate attack on shotcrete paste. In addition, the chloride ions' binding capacity can be 
well improved due to higher volume of C-S-H (hydrated calcium silicate) gels in fly ash binders [41]. Free chloride ions may be bundled by C-S-H or C-A-H (hydrated calcium aluminate) to form Friedel's salt, thus blocking the tiny pores. As a result, sulfate attack on shotcrete can be mitigated in the presence of chloride. In sum, shotcrete mixtures made by binary binders incorporating $10 \% \mathrm{SF}$ as partial replacement of OPC can facilitate sulfate attack on shotcrete, regardless of the presence of chloride or not. Addition of fly ash as partial replacement of OPC proved to be a valid countermeasure to reduce the degree of surface deterioration. In addition, concomitance of chloride in sulfate solutions can mitigate sulfate-induced deterioration on shotcrete, due to the block effect caused by the prior form of Friedel's salt.

3.1.2. Mass Variation. After 10 months of continuous full immersion in both erosion solutions (S and SC), all shotcrete specimens underwent variation of mass. Mass variations for shotcrete specimens made by single and blended binders after 10 months of full immersion in erosion solutions ( $\mathrm{S}$ or SC) are reported in Table 4.

Overall, PC and FA10 specimens had a mass gain, while a slight loss of mass was found from SF10 specimens. More specifically, the maximal mass gain occurred from PC55 specimens, which was $2.13 \%$ in S solutions and $1.78 \%$ in SC solutions, respectively. Mass loss of SF10 specimens was $0.77 \%$ in S solutions and $0.22 \%$ in SC solutions, respectively. The mass variation of various shotcrete specimens follows: PC55 $>$ PC45 > PC35 > FA10 > SF10. Clearly, the mass gain owed to water absorption, further hydration of binders and sulfate expansive products. The mass loss of SF10 attributed to surface spalling and the formation of thaumasite, which was expounded above. Meanwhile, a higher $\mathrm{w} / \mathrm{b}$ ratio resulted in a larger mass gain in PC specimens. This may be due to a higher $\mathrm{w} / \mathrm{b}$ ratio leads to higher water permeability and larger volume of pores on shotcrete pastes, thus giving rise to larger amount of ettringite formation and accumulation in these pores. In addition, the mass variation of a same type of shotcrete specimens was less in SC solutions compared to those in $\mathrm{S}$ solutions. This may be due to lower amount of secondary ettringite formed in SC solutions than in S solutions, due to inhibition by Friedel's salt. Clearly, the specimens incorporating 10\% FA exhibited the best resistance to both S and SC solutions' attacks, followed by PC specimens with low w/b ratio. SF10 specimens displayed the worst behavior under sulfate attack. In addition, the specimens in SC solutions showed less mass change than those in $S$ solutions.

3.1.3. Compression Strength Variation. Compressive strength variations for various shotcrete specimens incorporating different SCMs after 10 months of continuously full immersion in S and SC solutions are listed in Table 4. As a whole, all shotcrete specimens immersed in S and SC solutions suffered from strength loss, which indicated deterioration and damage. The strength loss of various shotcrete specimens follows: SF10 > PC55 $>$ PC45 $>$ PC35 $>$ FA10. The
TABLE 4: Variation of mass and compressive strength of various shotcrete specimens after exposure.

\begin{tabular}{|c|c|c|c|c|c|c|c|c|}
\hline \multirow{3}{*}{ Type } & \multicolumn{4}{|c|}{$\begin{array}{l}\text { Full immersion for } 10 \\
\text { months }\end{array}$} & \multicolumn{4}{|c|}{$\begin{array}{l}\text { Partial immersion with } \\
\text { cycle of temperature and } \\
\text { RH for } 5 \text { months }\end{array}$} \\
\hline & \multicolumn{2}{|c|}{$\begin{array}{c}\text { Mass } \\
\text { variation } \\
(\%)\end{array}$} & \multicolumn{2}{|c|}{$\begin{array}{l}\text { Compressive } \\
\text { strength } \\
\text { variation }(\%)\end{array}$} & \multicolumn{2}{|c|}{$\begin{array}{c}\text { Mass } \\
\text { variation } \\
(\%)\end{array}$} & \multicolumn{2}{|c|}{$\begin{array}{l}\text { Compressive } \\
\text { strength } \\
\text { variation } \\
(\%)\end{array}$} \\
\hline & $S$ & & & & c & & & \\
\hline & & & & & ( & & & \\
\hline & & & & & -0 & & & \\
\hline C5 & 2.13 & & -9 & -7.12 & -0.59 & 0.32 & -6.74 & -5.27 \\
\hline & & & & & -2.74 & & & 2.14 \\
\hline 510 & -0.71 & 0.22 & -15.26 & -10.6 & -3.86 & -3.49 & -7.41 & -6.2 \\
\hline
\end{tabular}

maximal loss of strength happened in SF10 specimens, i.e., $15.26 \%$ in S solutions and $10.6 \%$ in SC solutions, respectively. This is as expected because the formation of thaumasite, along with ettringite and gypsum, seriously deteriorated SF10, which was confirmed above and by previous reports [39]. It is clear that the FA10 showed superior performance under sulfate or sulfate-chloride attacks compared to other mixtures. However, shotcrete specimens incorporating $10 \%$ SF exhibited the lowest resistance to sulfate or sulfate-chloride attacks under full immersion regime. Thus, the use of silica fume as a partial replacement of OPC is not suitable for shotcrete under sulfate bearing environments. In addition, the specimens in SC solutions showed less loss of strength than those in $\mathrm{S}$ solutions. These findings are in line with the results of mass and visual inspection, also conforming well to recent reports $[39,41]$.

\subsection{Partial Immersion with Cycling Temperature and $R H$}

3.2.1. Visual Inspection. For all specimens in partial immersion regime, white efflorescence appeared on surface of specimen portion above the solution level (upper portion) after one cycle. These white substances may be the deposition of soluble sodium sulfate salt (i.e., mirabilite). Results of SEM and EDX analysis from fragment samples from upper portion of specimens confirmed that white efflorescence was sodium sulfate $[2,19]$.

They came from salt solutions and moved up by capillary action and diffusion, due to concentration gradient as a result from moisture evaporation in upper portion of shotcrete specimens. Figure 5 depicts various shotcrete specimens after partial immersion in S solution with cycling temperature and RH for 5 months. For PC specimens, it can be observed that the amount of efflorescence follows PC55 > PC45 > PC35. Thus, higher w/b ratios may facilitate physical sulfate attack on shotcrete. It has been reported that higher $\mathrm{w} / \mathrm{b}$ ratios facilitate physical sulfate attack on concrete materials, due to the higher permeability and porosity of concrete pastes with high w/b ratios [19]. Clearly, this conclusion is also suitable for shotcrete under sulfate attack.

For specimens made by binary binders, specimens containing $10 \%$ silica fume (SF10) exhibited more severe 
spalling along the edges and corners than that containing $10 \%$ fly ash (FA10). This may be due to that the finer pore structure of SF10 leads to higher capillary suction, as confirmed by MIP results. Thus, more possibility of salt crystallization occurred on the specimen surface of upper portion. Under cycling of temperature and $\mathrm{RH}$, phase transformation between mirabilite and thenardite took place on the surface layer of specimens [42]. Such repetitive crystallization of thenardite and mirabilite due to cyclic wetting and drying was responsible for the surface deterioration of shotcrete specimens exposed to sulfate solutions.

Partial replacement of OPC by SCMs can refine the pore structure and reduce the permeability of shotcrete, due to a reduction of the $\mathrm{C}_{3} \mathrm{~A}$ content in the binder (dilution effect), along with the consumption of calcium hydroxide $(\mathrm{CH})$ in pozzolanic reactions [42]. However, this may not result in positive effect on the resistance to physical sulfate attack, since finer pore structure may lead to high capillary suction [18]. This is a powerful accomplice to physical sulfate attack on shotcrete. As expected, the deterioration degrees of specimens made by binary binders were higher than that made by pure OPC.

This phenomenon also existed in the presence of chloride ions. Figure 6 presents various shotcrete specimens after partial immersion in SC solution with cycling temperature and RH for 5 months. Clearly, addition of fly ash or silica fume as partial replacement of OPC can facilitate physical sulfate attack on shotcrete. In addition, the presence of chloride may mitigate the deterioration caused by sulfate expansive products, due to the formation of Friedel's salt.

3.2.2. Mass Variation. Mass variations of specimens made by different binders after partial immersion in S and SC solutions with cycling temperature and $\mathrm{RH}$ for 5 months are also provided in Table 4 . The specimens made by binary binders suffered from mass loss in both S and SC solutions. This is due to spalling at edges and corners of specimens caused by salt crystallization. This indicates that partial replacement of OPC by fly ash or silica fume has adverse impact on the resistance to physical sulfate attack. For PC specimens, a higher $\mathrm{w} / \mathrm{b}$ ratio results in more mass loss. This means that lowering the $\mathrm{w} / \mathrm{b}$ ratio can enhance the resistance to physical sulfate attack on shotcrete, by decreasing porosity. Overall, the mass loss of specimens made by binary binders was more severe than those made by pure OPC, since more spalling occurred.

\subsubsection{Compression Strength Variation. Compressive} strength variations for various shotcrete specimens incorporating different SCMs after 5 months of partial immersion in $\mathrm{S}$ and $\mathrm{SC}$ solutions with cycling temperature and $\mathrm{RH}$ are presented in Table 4. All shotcrete specimens that were partially immersed in S and SC solutions suffered from strength loss, except for FA10. The strength loss of different specimens follows: SF10 > PC55 > PC45 > PC35 > FA10. For $\mathrm{PC}$ specimens, the higher $\mathrm{w} / \mathrm{b}$ ratio exhibited less resistance to efflorescence, thus resulting in more loss of strength. Note that FA10 specimens gained compressive strength of $1.42 \%$ in S solutions and $2.14 \%$ in SC solutions, respectively. However, FA10 specimens showed more surface spalling and mass loss than those made by pure OPC. It is well acknowledged that binders incorporating SCMs such as fly ash can refine porosity, thus to increase capillary suction. Such improvement may increase the risk of physical sulfate attack on cement-based materials, since the supply of sulfate ions in drying portion of specimens mainly depends on capillary rise in tiny pore systems [20]. This is confirmed via the performance of SF10 specimens, which displayed more loss of strength than those made by pure OPC after 5 months under physical sulfate attack. However, it does not work for FA10 specimens. It is well known that fly ash, as an excellent mineral admixture as a partial replacement of OPC, is prominent in enhancing the long-term strength of cementbased materials. However, the use of fly ash should pay the price of a reduction in early-age strength of concrete. Generally, this deficiency can be improved by the addition of silica fume, especially for shotcrete, since partial replacement of OPC by silica fume can significantly improve the early-age strength of shotcrete. This is allimportant for shotcrete materials, since early-age strength of shotcrete is crucial in the design of these materials. However, silica fume has high content of silicium and low content of $\mathrm{Al}_{2} \mathrm{O}_{3}$. Such low$\mathrm{Al}_{2} \mathrm{O}_{3}$ system is favor to the form of ettringite, even thaumasite if other conditions were fulfilled, such as low temperature. Anyhow, silica fume exhibits adverse impact on both chemical and physical sulfate attacks in current trials. This finding is also in accordance with that reported in $[18-20,24]$. Probably, the gain of strength for FA10 specimens attributed to delayed enhancement in strength during the later exposure period. This point should require further attention, thus ongoing trials keep going on.

As a whole, shotcrete specimens containing 10\% fly ash exhibited the best resistance to physical sulfate attack, while this is just the reverse for those containing $10 \%$ silica fume. Thus, fly ash seems to be a better mineral admixture to increase the resistance to physical sulfate attack. However, the use of silica fume as partial replacement of OPC should be cautious in practical. In addition, the specimens in SC solutions showed less loss of strength than those in S solutions. This indicates that the presence of chloride can mitigate damage caused by physical sulfate attack.

Results of microanalysis from powder samples confirmed that the periodic phase transformation between mirabilite and thenardite was the main driving mechanism of surface spalling, which is the typical feature of physical sulfate attack on shotcrete. In addition, it can be seen that weak peaks of ettringite and gypsum existed in the powder samples from the above portion of deteriorating specimens. This indicates that some sulfate may also react with $\mathrm{CH}$ and $\mathrm{C}-\mathrm{A}-\mathrm{H}$ to form these expansive products. Therefore, chemical sulfate attack also occurred under the exposure regime, aiming at inducing pure physical sulfate attack. Generally, it is regarded that physical sulfate attack cannot affect concrete strength, since the core is not influenced [19]. However, loss of strength still took place in concrete under physical attack. This seems to be inconsistent with the above findings and previous reports [31]. 


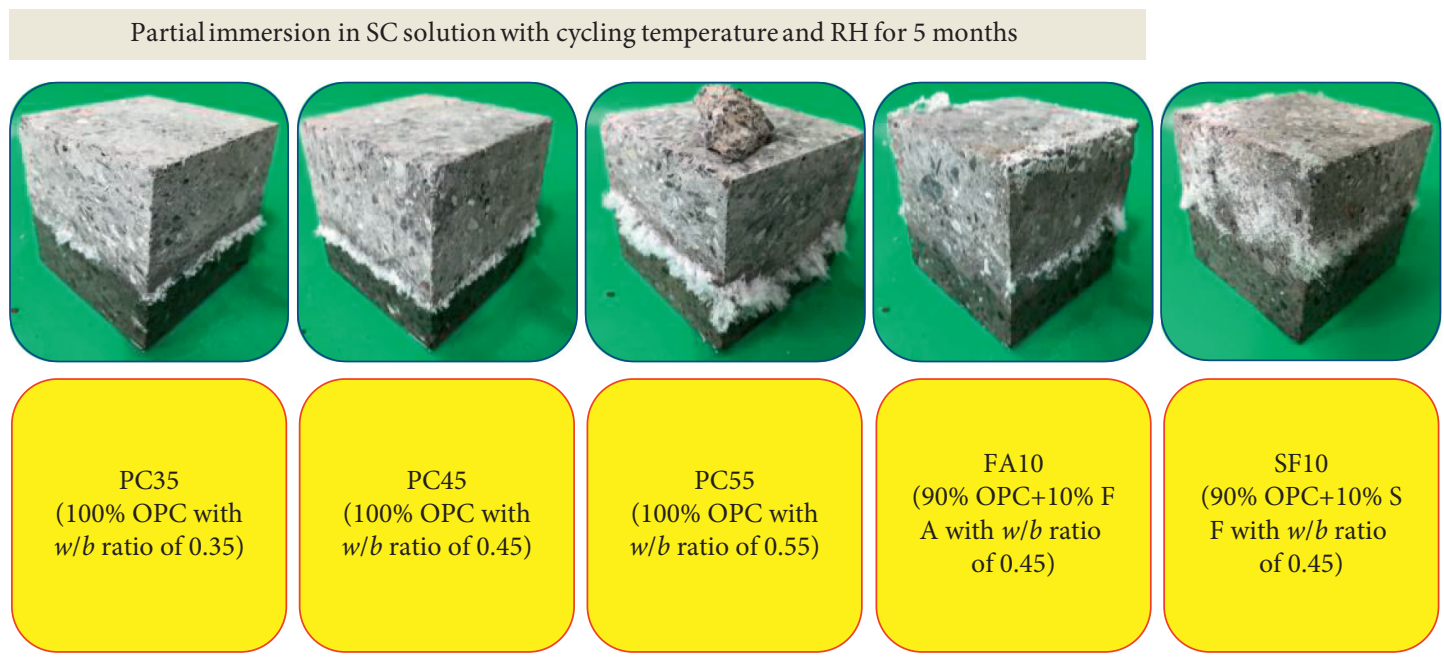

FIGURE 6: Visual appearance of various shotcrete specimens partially immersed in SC solutions subjected to cycles of temperature and RH for 5 months.
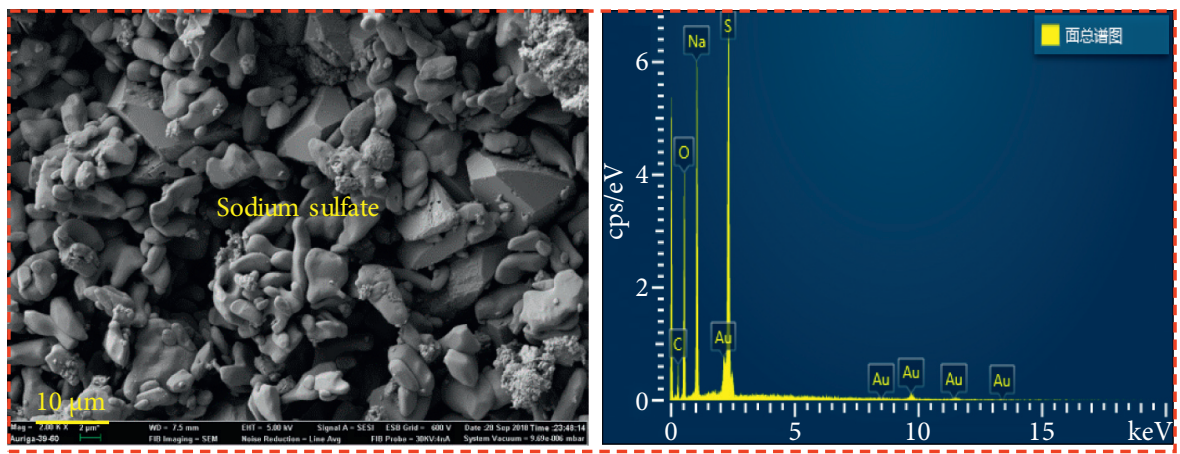

Figure 7: Test result of powder samples taken from the shotcrete specimen on the surface or superficial layer beneath the surface.

Different exposure regimes in lab-scale tests aim at inducing different attack mechanisms. For example, full immersion is responsible for chemical attack, while physical attack generally happens under partial immersion [28]. Loss of strength is the typical characteristics of chemical sulfate attack on cement-based materials, since $\mathrm{C}_{3} \mathrm{~A}$ and hydrated aluminate phases were destroyed by sulfate [2]. Under physical sulfate attack, deterioration often stays on the specimen surface or beneath the surface, in the form of spalling and flaking [19]. Crystallization and phase transformation of sulfate salt may be the main driving mechanism of this attack [20]. Generally, it is regarded that physical sulfate attack does not affect strength of concrete. However, small size specimens with high specific surface area were primarily used in the lab to perform physical sulfate attack test on concrete. These specimens can be completely destroyed under harsh physical attack regime, such as drastic drying-wetting cycles or high-concentration sodium sulfate solutions. Therefore, larger specimens $\left(100 \mathrm{~mm}^{3}\right.$ cubes) were used to experience physical attack in this study. Under this consideration, the test period was highly increased due to that specimens with large specific surface area were hard to be attacked in comparison with small specimens. Fortunately, some important details are found. By the microanalysis of samples from interior concrete core, no sulfate reaction products such as ettringite or gypsum were detected. More interesting, traces of ettringite and $\mathrm{CH}$ were simultaneously detected in the powder samples taken from around $20 \mathrm{~mm}$ beneath the specimen surface. However, no sodium sulfate crystal was found from these powder samples. In other words, sodium sulfate crystals such as mirabilite and thenardite were only detected on the specimen surface or the superficial layer beneath the surface, as shown in Figure 7.

This indicates that shotcrete cores will not be deteriorated by salt crystallization subjected to physical sulfate attack. Meanwhile, coexistence of chemical and physical sulfate attack on conventional physical sulfate attack on shotcrete. Evaporation of water in the upper portion of shotcrete specimens' results in a remarkable gradient of concentration between the upper portion and the lower portion, especially near the surface. This gradient of concentration significantly affects the transportation kinetics of sulfate ions in the matrix. If chloride exists, the ingress of sulfate ions into core may be impeded by the prior formation of Friedel's salt, since the penetration rate of free chloride ions in concrete is faster than that of sulfate ions. Therefore, physical spalling mainly deteriorates the surface of specimens, but chemical reactions 
may attack concrete interior. That is why the loss of strength from shotcrete specimens under physical sulfate attacks in the current study. In addition, the current tests will be continuous; more details concerning external sulfate attack on shotcrete specimens $\left(100 \mathrm{~mm}^{3}\right.$ cubes) in the presence of chloride will be obtained. In fact, this consideration of the specimen size is closer to practical, such as shotcrete lining of a tunnel. However, shotcrete lining is typically attacked by groundwater contaminated by pernicious species at only one surface. Such exposure regime is far away from that of piers or piles. Thus, the resulting transportation kinetics and damage mechanism on shotcrete may be different. This point requires further attention, since it is vital in the shotcrete design of practical engineering.

\section{Conclusions}

Durability of shotcrete with addition of mineral admixtures under external sulfate attack in the presence of chloride was investigated. From the present study, the following conclusions can be drawn:

) (iUnder conventional chemical sulfate attack on shotcrete, loss of strength is the typical feature. For partial immersion with cycling temperature and $\mathrm{RH}$, physical sulfate attack in the form of surface spalling is the main type of deterioration.

(ii) Shotcrete specimens incorporating $10 \% \mathrm{FA}$ as partial replacement of OPC achieved adequate resistance to chemical sulfate attack. However, such specimens suffered from surface deterioration under the exposure of partial immersion with cycling temperature and $\mathrm{RH}$. Shotcrete with addition of $10 \%$ SF exhibited the least resistance to both chemical and physical sulfate attack, regardless of the presence of chloride. This is due to that low aluminium oxide $\left(\mathrm{Al}_{2} \mathrm{O}_{3}\right)$ and tri-calcium aluminate (C3A) content of silica fume system is favor to the formation of ettringite and thaumasite.

(iii) Shotcrete specimens with lower w/b ratios show good resistance to both chemical and physical sulfate attack, due to its higher compactness and lower porosity and permeability.

(iv) The concomitant presence of chloride can mitigate the deterioration caused by external sulfate attack. This is due to that chloride combined $\mathrm{C}_{3} \mathrm{~A}$ and calcium hydroxide $(\mathrm{CH})$ to form Friedel's salt. This product can block shotcrete pores, thereby to forestall the further ingress of sulfate ions.

(v) Under physical sulfate attack on shotcrete, the specimen size has an influence on the transportation kinetics of sulfate ions in matrix, subsequently the nature of attack mechanism. For $100 \mathrm{~mm}^{3}$ cubic specimens used in this study, salt crystallization was only detected in the surface layer of specimens. Shotcrete cores were at risk of chemical sulfate attack. The effect of the specimen size on physical sulfate attack should require further attention.

\section{Data Availability}

The data used to support the findings of this study are included within the article.

\section{Conflicts of Interest}

The authors declare that they have no conflicts of interest.

\section{Acknowledgments}

This work was sponsored by the China Postdoctoral Science Foundation (Grant no. 2021M693919), the Natural Science Foundation of Chongqing, China (Grant no. cstc2020jcyjbshX0007), and the National Natural Science Foundation of China (nos. 51808082 and 52008066).

\section{References}

[1] S. W. Tang, Y. Yao, C. Andrade, and Z. J. Li, "Recent durability studies on concrete structure," Cement and Concrete Research, vol. 78, pp. 143-154, 2015.

[2] Z. Zhang, X. Jin, and W. Luo, "Long-term behaviors of concrete under low-concentration sulfate attack subjected to natural variation of environmental climate conditions," $\mathrm{Ce}$ ment and Concrete Research, vol. 116, pp. 217-230, 2019.

[3] Z. Zhang, X. Jin, and W. Luo, "Mechanical responses of shotcrete specimens in direct shear tests," Construction and Building Materials, vol. 188, pp. 305-313, 2018.

[4] N. Shanahan and A. Zayed, "Cement composition and sulfate attack," Cement and Concrete Research, vol. 37, no. 4, pp. 618-623, 2007.

[5] Y. Zhao, H. Ding, and W. Jin, "Development of the corrosionfilled paste and corrosion layer at the steel/concrete interface," Corrosion Science, vol. 87, pp. 199-210, 2014.

[6] Y. Zhao, X. Zhang, and W. Jin, "Influence of environment on the development of corrosion product-filled paste and a corrosion layer at the steel/concrete interface," Corrosion Science, vol. 124, 2017.

[7] C. Fu, N. Jin, H. Ye, X. Jin, and W. Dai, "Corrosion characteristics of a 4-year naturally corroded reinforced concrete beam with load-induced transverse cracks," Corrosion Science, vol. 117, 2017.

[8] F. Bellmann, W. Erfurt, and H.-M. Ludwig, "Field performance of concrete exposed to sulphate and low ph conditions from natural and industrial sources," Cement and Concrete Composites, vol. 34, no. 1, pp. 86-93, 2012.

[9] J. L. Provis, A. Palomo, and C. Shi, "Advances in understanding alkali-activated materials," Cement and Concrete Research, vol. 78, pp. 110-125, 2015.

[10] K. L. Scrivener, P. Juilland, and P. J. M. Monteiro, "Advances in understanding hydration of portland cement," Cement and Concrete Research, vol. 78, pp. 38-56, 2015.

[11] M. Collepardi, "A state-of-the-art review on delayed ettringite attack on concrete," Cement and Concrete Composites, vol. 25, no. 4-5, pp. 401-407, 2003.

[12] A. Ghazy and M. T. Bassuoni, "Resistance of concrete to different exposures with chloride-based salts," Cement and Concrete Research, vol. 101, no. 11, pp. 144-158, 2017.

[13] M. Zajac, P. Durdzinski, C. Stabler, J. Skocek, D. Nied, and M. Ben Haha, "Influence of calcium and magnesium carbonates on hydration kinetics, hydrate assemblage and microstructural development of metakaolin containing 
composite cements," Cement and Concrete Research, vol. 106, pp. 91-102, 2018.

[14] K. Sotiriadis, E. Nikolopoulou, and S. Tsivilis, "Sulfate resistance of limestone cement concrete exposed to combined chloride and sulfate environment at low temperature," $\mathrm{Ce}$ ment and Concrete Composites, vol. 34, no. 8, pp. 903-910, 2012.

[15] M. Maes and N. De Belie, "Resistance of concrete and mortar against combined attack of chloride and sodium sulphate," Cement and Concrete Composites, vol. 53, no. 10, pp. 59-72, 2014.

[16] I. Tai, S. H. P. Cavalaro, I. Segura, and A. Aguado, “Alternative methodology to consider damage and expansions in external sulfate attack modeling," Cement and Concrete Research, vol. 63 , no. 63, pp. 105-116, 2014.

[17] F. Girardi, W. Vaona, and R. Di Maggio, "Resistance of different types of concretes to cyclic sulfuric acid and sodium sulfate attack," Cement and Concrete Composites, vol. 32, no. 8, pp. 595-602, 2010.

[18] M. Nehdi and M. Hayek, "Behavior of blended cement mortars exposed to sulfate solutions cycling in relative humidity," Cement and Concrete Research, vol. 35, no. n 4, pp. 731-742, 2005.

[19] M. L. Nehdi, A. R. Suleiman, and A. M. Soliman, "Investigation of concrete exposed to dual sulfate attack," Cement and Concrete Research, vol. 64, pp. 42-53, 2014.

[20] M. T. Bassuoni and M. M. Rahman, "Response of concrete to accelerated physical salt attack exposure," Cement and Concrete Research, vol. 22, 2015.

[21] X. Zhang, M. Li, L. Tang et al., "Corrosion induced stress field and cracking time of reinforced concrete with initial defects: analytical modeling and experimental investigation," Corrosion Science, vol. 120, pp. 158-170, 2017.

[22] M. Otieno, "Sensitivity of chloride-induced corrosion rate of steel in concrete to cover depth, crack width and concrete quality," Materials and Structures, vol. 50, no. 1, p. 9, 2017.

[23] A. Michel, A. O. S. Solgaard, B. J. Pease, M. R. Geiker, H. Stang, and J. F. Olesen, "Experimental investigation of the relation between damage at the concrete-steel interface and initiation of reinforcement corrosion in plain and fibre reinforced concrete," Corrosion Science, vol. 77, no. 6, pp. 308-321, 2013.

[24] W. Nguyen, J. F. Duncan, G. Jen, and C. P. Ostertag, "Influence of matrix cracking and hybrid fiber reinforcement on the corrosion initiation and propagation behaviors of reinforced concrete," Corrosion Science, vol. 140, 2018.

[25] K. Sotiriadis, E. Nikolopoulou, S. Tsivilis, A. Pavlou, E. Chaniotakis, and R. N. Swamy, "The effect of chlorides on the thaumasite form of sulfate attack of limestone cement concrete containing mineral admixtures at low temperature," Construction and Building Materials, vol. 43, pp. 156-164, 2013.

[26] F. Chen, J. Gao, B. Qi, D. Shen, and L. Li, "Degradation progress of concrete subject to combined sulfate-chloride attack under drying-wetting cycles and flexural loading," Construction and Building Materials, vol. 151, pp. 164-171, 2017.

[27] B. Frank, M. . Bernd, and J. Stark, "Influence of sulfate solution concentration on the formation of gypsum in sulfate resistance test specimen," Cement and Concrete Research, vol. 36, no. 2, pp. 358-363, 2006.

[28] M. T. Bassuoni and M. L. Nehdi, "Durability of self-consolidating concrete to different exposure regimes of sodium sulfate attack," Materials and Structures, vol. 42, no. 8, pp. 1039-1057, 2009.
[29] M. T. Bassuoni and M. L. Nehdi, "Durability of self-consolidating concrete to sulfate attack under combined cyclic environments and flexural loading," Cement and Concrete Research, vol. 39, no. 3, pp. 206-226, 2009.

[30] R. M. Espinosa, L. Franke, and G. Deckelmann, "Phase changes of salts in porous materials: crystallization, hydration and deliquescence," Construction and Building Materials, vol. 22, no. 8, pp. 1758-1773, 2008.

[31] Z. Liu, D. Deng, G. D. Schutter, and Z. Yu, "Chemical sulfate attack performance of partially exposed cement and cement+fly ash paste," Construction and Building Materials, vol. 28, no. 1, pp. 230-237, 2012.

[32] R. J. Flatt, "Salt damage in porous materials: how high supersaturations are generated," Journal of Crystal Growth, vol. 242, no. 3-4, pp. 435-454, 2002.

[33] G. W. Scherer, "Stress from crystallization of salt," Cement and Concrete Research, vol. 34, no. 9, pp. 1613-1624, 2004.

[34] S. Zhutovsky and R. Douglas Hooton, "Experimental study on physical sulfate salt attack," Materials and Structures, vol. 50, no. 1, p. 54, 2017.

[35] Jgj/T 372-2016, Technical Specification for Application of Sprayed concrete, China Architecture \& Building Press, Beijing, China, 2016.

[36] Jgj 52-2006, Standard for Technical Requirements and Test Method of Sand and Crushed Stone (Or Gravel) for Ordinary Concrete, China Architecture \& Building Press, Beijing, China, 2016.

[37] Gb/T 50082-2009, Standard for Test Methods of Long-Term Performance and Durability of Ordinary concrete, China Architecture \& Building Press, Beijing, China, 2009.

[38] Gb 50081-2002, Standard for Method of Mechanical Properties on Ordinary Concrete, China Architecture and Building Press, Beijing, China, 2002.

[39] M. F. Najjar, M. L. Nehdi, A. M. Soliman, and T. M. Azabi, "Damage mechanisms of two-stage concrete exposed to chemical and physical sulfate attack," Construction and Building Materials, vol. 137, pp. 141-152, 2017.

[40] M. Jin, S. Gao, L. Jiang, H. Chu, M. Lu, and F. F. Zhi, "Degradation of concrete with addition of mineral admixture due to free chloride ion penetration under the effect of carbonation," Corrosion Science, vol. 138, 2018.

[41] T. Aye and C. T. Oguchi, "Resistance of plain and blended cement mortars exposed to severe sulfate attacks," Construction and Building Materials, vol. 25, no. 6, pp. 2988-2996, 2011.

[42] J.-P. Won, U.-J. Hwang, and S.-J. Lee, "Enhanced long-term strength and durability of shotcrete with high-strength C $12 \mathrm{~A}$ 7 mineral-based accelerator," Cement and Concrete Research, vol. 76, pp. 121-129, 2015.

[43] P. Choi, J. H. Yeon, and K.-K. Yun, "Air-void structure, strength, and permeability of wet-mix shotcrete before and after shotcreting operation: the influences of silica fume and air-entraining agent," Cement and Concrete Composites, vol. 70, pp. 69-77, 2016.

[44] P. Bamonte, P. G. Gambarova, and A. Nafarieh, "Hightemperature behavior of structural and non-structural shotcretes," Cement and Concrete Composites, vol. 73, pp. 42-53, 2016.

[45] P. B. Trujillo, M. Jolin, B. Massicotte, and B. Bissonnette, "Bond strength of reinforcing bars encased with shotcrete," Construction and Building Materials, vol. 169, pp. 678-688, 2018.

[46] M. Khooshechin and J. Tanzadeh, "Experimental and mechanical performance of shotcrete made with nanomaterials 
and fiber reinforcement," Construction and Building Materials, vol. 165, pp. 199-205, 2018.

[47] J. Wang, D. Niu, and Y. Zhang, "Mechanical properties, permeability and durability of accelerated shotcrete," Construction and Building Materials, vol. 95, pp. 312-328, 2015.

[48] D.-T. Niu, Y.-D. Wang, R. Ma, J.-B. Wang, and S.-H. Xu, "Experiment study on the failure mechanism of dry-mix shotcrete under the combined actions of sulfate attack and drying-wetting cycles," Construction and Building Materials, vol. 81, pp. 74-80, 2015.

[49] J. O. Ukpata, P. A. Muhammed Basheer, and L. Black, "Expansion of CEM I and slag-blended cement mortars exposed to combined chloride-sulphate environments," Cement and Concrete Research, vol. 123, Article ID 105794, 2019.

[50] J. O. Ukpata, P. A. M. Basheer, and L. Black, "Slag hydration and chloride binding in slag cements exposed to a combined chloride-sulphate solution," Construction and Building $\mathrm{Ma}$ terials, vol. 195, pp. 238-248, 2019.

[51] M. Fathima Suma, M. Santhanam, and A. V. Rahul, "The effect of specimen size on deterioration due to external sodium sulphate attack in full immersion studies," Cement and Concrete Composites, vol. 114, Article ID 103806, 2020.

[52] Y. Cao, L. Guo, B. Chen, and J. Wu, "Thermodynamic modelling and experimental investigation on chloride binding in cement exposed to chloride and chloride-sulfate solution," Construction and Building Materials, vol. 246, Article ID 118398, 2020.

[53] ASTM D4404, Standard Test Method for Determination of Pore Volume and Pore Volume Distribution of Soil and Rock by Mercury Intrusion Porosimetry, ASTM International, West Conshohocken, PA, USA, 2010. 